\title{
A Preliminary Study on the Fruit Drop Mechanism of Zizyphus Jujuba 'Zhanshanmizao'
}

\author{
Si Ren ${ }^{1, a}$, Wenjun Yang ${ }^{1, b}$, Bin Zhou ${ }^{1, \mathrm{c}}$, Tao Tao $^{1, \mathrm{~d}}$ and Qunxian Deng ${ }^{1, \mathrm{e}^{*}}$ \\ ${ }^{1}$ College of Horticulture, Sichuan Agricultural University, Chengdu, Sichuan, China \\ a624426972@qq.com, b522847767@qq.com, c306199251@qq.com, d497993389@qq.com, \\ e1324856299@qq.com
}

\begin{abstract}
Keywords: Zizyphus Jujuba 'Zhanshanmizao'; Fruit drop rate; Tree vigor; Organic nutrients Abstract: In order to solve the problem of high fruit drop rate of Zizyphus Jujuba 'Zhanshanmizao', this experiment used Z. Jujuba 'Zhanshanmizao' as material, throught measuring the fruit drop rate and organic nutrient changes with different tree vigor, to study the dynamic change and drop mechanism of fruit drop. The results showed that there were two fruit drop peaks in fruit growing period, which were early June and late August respectively. Different tree vigor has influence on the fruit drop rate of Z. Jujuba 'Zhanshanmizao', the general trend was weak tree > strong tree > medium tree. The soluble sugar content and soluble protein content significantly affected the fruit drop rate, the difference of soluble sugar content in the fallen fruit compared with the normal fruit reached the maximum in early July, while the difference of soluble protein content between the fallen fruit and the normal fruit reached maximum in the early and middle stages of fruit ripening. However, titratable acid content and $\mathrm{Vc}$ content have little effect on the fruit drop rate.
\end{abstract}

\section{Introduction}

Zizyphus Jujuba 'Zhanshanmizao' is a plant belong to Rhanmaceae.R.Br. Its taste is sweet, tender, crisp, and has high nutritional value. It is an excellent variety that has been welcomed by the market in recent years [1]. Z. Jujuba 'Zhanshanmizao' is the same as other jujube varieties. has a severe fruit drop phenomenon [2]. J.H. Li divided the fruit drop period of the jujube into three sections [3], but studies in recent years have shown that there are only two peaks of the fruit drop on Jun-jujube and Zizyphus Jujuba cv. Dongzao [4,5]. There are many factors influencing the fruit drop of jujube trees. Studies on Zizyphus Jujuba cv Lizao showed that tree vigor is one of the factors affecting the fruit drop rate of jujube trees. the results is that the amount of the fallen fruit was weak tree > strong tree > medium tree [6]. Jujube fruit is rich in organic nutrients, such as soluble sugar, soluble protein, titratable acid, vitamin C, etc. [7,8]. Studies on Z. Jujuba cv. Dongzao showed that soluble sugars and soluble proteins with low contents in jujube fruit are related to the occurrence of fruit drop [5]. However, studies on apricot show that the soluble protein content of the fallen fruit is higher than that of the normal fruit [9]. So far, no studies have reported whether titratable acid and vitamin $\mathrm{C}$ have an effect on fruit drop. Although there have been some reports on the fruit drop mechanism of jujube tree in recent years, the study of the physiological mechanism of the fruit drop in Z. Jujuba 'Zhanshanmizao' is still lacking. Therefore, this experiment selected the Z. Jujuba 'Zhanshanmizao' of different tree vigor, analyzed the change of fruit drop dynamic and organic nutrients in it, to initially revealing the physiological mechanism of fruit drop in the general cultivation conditions, and provide a scientific basis for the targeted solution to the problem of fruit drop of $Z$. Jujuba 'Zhanshanmizao'.

\section{Materials and Methods}

Materials. The experiment was conducted on June 18 th, 2017, sampling site is located in Yonglian Village, Yongxin Town, Santai County, Mianyang. The soil on the test site was loam, and the soil and fertilizer conditions were consistent and well managed. The experimental material is Z. Jujuba 'Zhanshanmizao' which is six years old. Plant spacing is $2 \mathrm{~m}$ and row spacing is $3 \mathrm{~m}$. 
Experimental Design. According to the growth status of plants, the test plants were divided into three levels: strong, medium, and weak. The specific index parameters are shown in Table 1. Two trees were selected for each tree vigor and repeated three times. A total of 18 plants were selected. Sampling was started from the young fruit period (June $18 \mathrm{th}, 2017$ ) until the fruit maturation period (August 29 th, 2017), was sampled every 15 days for a total of 6 times. The samples included the normal fruit and the fallen fruit that which is drop when trunk shakes on the day of the investigation. The fallen fruit and the normal fruit were brought back to the laboratory with ice boxes for the determination of experimental index.

Table 1 Index parameters for grading tree vigor

\begin{tabular}{cccc}
\hline Index & Strong tree & Medium tree & Weak tree \\
\hline Trunk girth $(\mathrm{cm})$ & $26-27$ & $24-25$ & $20-21$ \\
Tree height $(\mathrm{cm})$ & $280-290$ & $240-250$ & $200-210$ \\
Number of Secondary branch & $15-17$ & $13-15$ & $11-13$ \\
Length of Secondary branch $(\mathrm{cm})$ & $22-23$ & $21-22$ & $20-21$ \\
\hline
\end{tabular}

Index measurement. Take a normal growth secondary branch of 4 directions in the middle and upper part of the crown of the plant as the observation branch. The number of flowers and fruits were recorded every 15 days to calculate the fruit drop rate and investigate the fruit drop dynamics.

The content of soluble sugar was determined by anthrone colorimetry, and soluble protein content was determined by Coomassie Brilliant Blue G-250 method [10]. The titratable acid content was determined by acid-base neutralization titration, and the vitamin $\mathrm{C}$ content was determined by 2,6-dichlorophenol phenol titration [11]

Statistical Analyses. Data was analyzed using SPSS Statistics 20.0 software for analysis of variance, setting significance level at $p<0.05$.

\section{Results and Discussion}

Dynamic Change of Fruit Drop. The trend of fruit drop dynamics in plant of three kinds of tree vigors is basically the same, from 6.1 to 7.2 , the fruit drop rate sharply rises, after 7.17 tends to be flat (Fig. 1). The fruit drop rate of the weak tree is higher than that of the other two kinds of tree vigors. The specific performance is weak tree $>$ strong tree $>$ medium tree. In addition, there are two peaks in the fruit drop of Z. Jujuba 'Zhanshanmizao'. The first peak of the fruit drop was from mid-late June to early July. The increase in the fruit drop rate of strong, medium, and weak tree was $37.4 \%, 36.0 \%$, and $38.0 \%$; the second peak of the fruit drop was in the middle and early August. The increase in the fruit drop rate of strong, middle, and weak tree was $7.6 \%, 6.6 \%$, and $7.6 \%$. The first drop rate is much stronger than the second. When the fruit was mature, the total fruit drop rate of strong, medium and weak tree reachd $97.97 \%, 97.76 \%$, and $98.28 \%$, respectively.

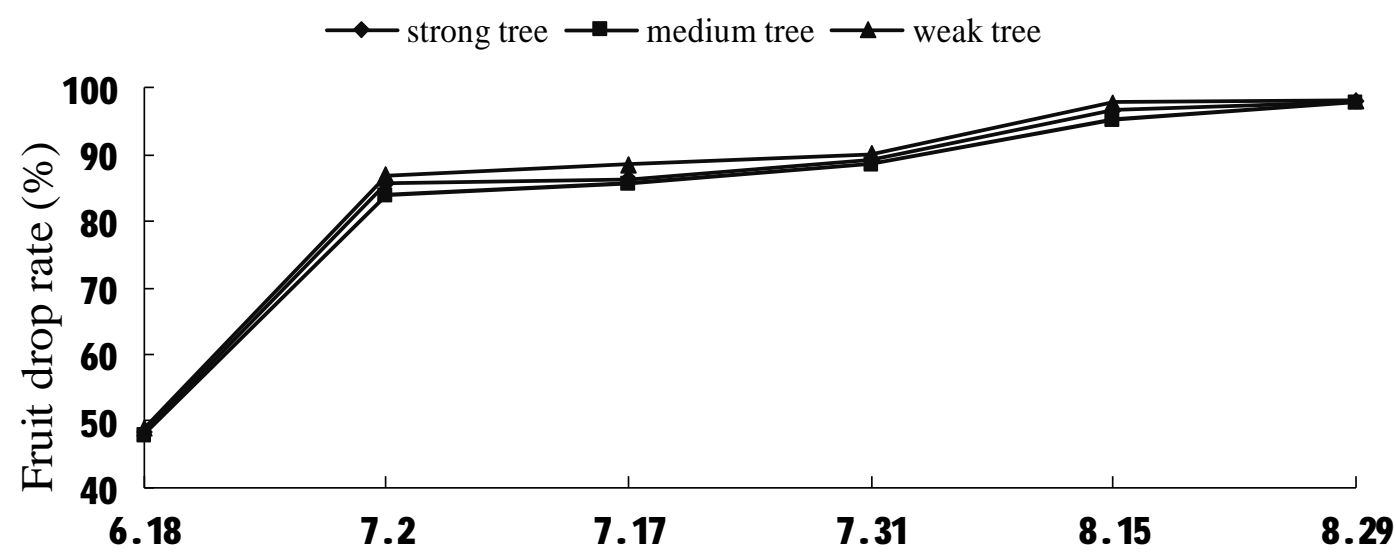

Observation time (mouth.date)

Fig. 1 Dynamic change of fruit drop of Z. Jujuba 'Zhanshanmizao' 
Changes of Soluble Sugar Content. The soluble sugar content of Z. Jujuba 'Zhanshanmizao' is all increased with the development of the fruit (Table 2). The content of soluble sugar in the medium tree was significantly higher than that of the strong and weak trees with the development of the fruit, and the weak tree was significantly lower than the strong tree, which was consistent with the performance of the fruit drop rate. Except the strong trees on 8.15, the medium tree on 6.18 and 8.15 and the weak tree on 7.2, the soluble sugar content of the fallen fruit was significantly lower than the normal fruit in the fruit development period of Z. Jujuba 'Zhanshanmizao'. Through analysis, it was found that on 7.17, the two kinds of fruit have the largest difference in soluble sugar content, the strong, medium and weak tree reached $9.38 \%, 8.02 \%$, and $8.14 \%$. Therefore, it is speculated that the decrease of soluble sugar content is one of the reasons that affect fruit drop, and it has a greater impact on the mid-stage of fruit development.

Table 2 Soluble sugar content in fruit of Z. Jujuba 'Zhanshanmizao'

\begin{tabular}{ccccccc}
\hline \multirow{2}{*}{$\begin{array}{c}\text { Time } \\
\text { (mouth.date) }\end{array}$} & \multicolumn{3}{c}{ Normal fruit $(\%)$} & \multicolumn{3}{c}{ Fallen fruit $(\%)$} \\
\cline { 2 - 7 } & tree & $\begin{array}{c}\text { Medium } \\
\text { tree }\end{array}$ & $\begin{array}{c}\text { Weak } \\
\text { tree }\end{array}$ & $\begin{array}{c}\text { Strong } \\
\text { tree }\end{array}$ & $\begin{array}{c}\text { Medium } \\
\text { tree }\end{array}$ & $\begin{array}{c}\text { Weak } \\
\text { tree }\end{array}$ \\
\hline 6.18 & $2.95 \pm 0.11 \mathrm{a}$ & $2.96 \pm 0.08 \mathrm{a}$ & $2.93 \pm 0.45 \mathrm{~b}$ & $2.91 \pm 0.06 \mathrm{c}$ & $2.95 \pm 0.03 \mathrm{a}$ & $2.91 \pm 0.09 \mathrm{c}$ \\
7.2 & $5.56 \pm 0.20 \mathrm{~b}$ & $5.59 \pm 0.02 \mathrm{a}$ & $5.49 \pm 0.89 \mathrm{c}$ & $5.45 \pm 0.12 \mathrm{~d}$ & $5.37 \pm 0.08 \mathrm{e}$ & $5.48 \pm 0.03 \mathrm{c}$ \\
7.17 & $7.57 \pm 0.09 \mathrm{~b}$ & $7.86 \pm 0.31 \mathrm{a}$ & $7.37 \pm 0.23 \mathrm{c}$ & $6.86 \pm 0.65 \mathrm{e}$ & $7.23 \pm 0.23 \mathrm{~d}$ & $6.77 \pm 0.64 \mathrm{f}$ \\
7.31 & $10.43 \pm 0.12 \mathrm{a}$ & $10.37 \pm 0.97 \mathrm{~b}$ & $10.19 \pm 0.29 \mathrm{c}$ & $10.04 \pm 0.24 \mathrm{~d}$ & $9.99 \pm 0.14 \mathrm{e}$ & $9.92 \pm 0.82 \mathrm{f}$ \\
8.15 & $17.39 \pm 0.36 \mathrm{bc}$ & $18.43 \pm 0.54 \mathrm{a}$ & $17.52 \pm 0.28 \mathrm{~b}$ & $16.99 \pm 0.18 \mathrm{~cd}$ & $18.39 \pm 1.20 \mathrm{a}$ & $16.87 \pm 0.91 \mathrm{~d}$ \\
8.29 & $21.45 \pm 0.43 \mathrm{c}$ & $23.11 \pm 1.02 \mathrm{a}$ & $20.43 \pm 1.42 \mathrm{e}$ & $21.21 \pm 0.45 \mathrm{~d}$ & $22.96 \pm 0.92 \mathrm{~b}$ & $19.84 \pm 0.65 \mathrm{f}$ \\
\hline
\end{tabular}

Values are means \pm standard errors. Means with the same letter within each row are not significantly different at $p<0.05$. Same as below.

Changes of Soluble Protein Content. The soluble protein content of Z. Jujuba 'Zhanshanmizao' in the young fruit period is relatively high, tends to be stable in the mid-stage of fruit development, and quickly rises in the early mature period, and then rapidly declines with the full development and maturation of the fruit (Table 3). By analysis of variance, the strong tree except on 7.17, the middle tree except on 8.15 , the weak tree except on $6.18,7.17,8.15$, and 8.29 , the soluble protein content of the normal fruit was significantly higher than the fallen fruit in other periods. In the strong tree, the difference of soluble protein content between the two kinds fruits on 6.18 and 7.2 was $24.35 \%$ and $15.17 \%$; in the middle tree, the difference of soluble protein content between the two kinds of fruit on 7.2 and 7.17 was was $22.49 \%$ and $37.56 \%$; in the weak tree, the difference of soluble protein content between the two kinds of fruit on 7.2 and 7.31 was $24.65 \%$ and $21.18 \%$. It can be seen that the soluble sugar content affects the fruit drop, and the impact period is mainly in the early and middle period of fruit growth, which is consistent with the peak of fruit drop dynamics.

Table 3 Soluble protein content in fruit of Z. Jujuba 'Zhanshanmizao'

\begin{tabular}{ccccccc}
\hline \multirow{2}{*}{$\begin{array}{c}\text { Time } \\
\text { (mouth.date) }\end{array}$} & \multicolumn{3}{c}{ Normal fruit $(\%)$} & \multicolumn{3}{c}{ Fallen fruit $(\%)$} \\
\cline { 2 - 7 } & $\begin{array}{c}\text { Strong } \\
\text { tree }\end{array}$ & $\begin{array}{c}\text { Medium } \\
\text { tree }\end{array}$ & $\begin{array}{c}\text { Weak } \\
\text { tree }\end{array}$ & $\begin{array}{c}\text { Strong } \\
\text { tree }\end{array}$ & $\begin{array}{c}\text { Medium } \\
\text { tree }\end{array}$ & $\begin{array}{c}\text { Weak } \\
\text { tree }\end{array}$ \\
\hline 6.18 & $29.24 \pm 0.98 \mathrm{a}$ & $24.21 \pm 2.13 \mathrm{c}$ & $23.15 \pm 1.35 \mathrm{~d}$ & $22.12 \pm 1.84 \mathrm{e}$ & $22.23 \pm 1.39 \mathrm{e}$ & $24.80 \pm 1.63 \mathrm{~b}$ \\
7.2 & $13.98 \pm 0.23 \mathrm{c}$ & $16.81 \pm 0.34 \mathrm{a}$ & $15.70 \pm 0.24 \mathrm{~b}$ & $11.86 \pm 0.34 \mathrm{e}$ & $13.03 \pm 1.21 \mathrm{~d}$ & $11.83 \pm 0.37 \mathrm{e}$ \\
7.17 & $12.12 \pm 0.23 \mathrm{e}$ & $14.03 \pm 0.29 \mathrm{c}$ & $14.6 \pm 0.46 \mathrm{~b}$ & $13.54 \pm 0.39 \mathrm{~d}$ & $8.76 \pm 0.83 \mathrm{f}$ & $15.79 \pm 0.24 \mathrm{a}$ \\
7.31 & $13.12 \pm 0.63 \mathrm{c}$ & $14.52 \pm 1.05 \mathrm{~b}$ & $14.73 \pm 0.78 \mathrm{a}$ & $12.98 \pm 0.87 \mathrm{~d}$ & $12.92 \pm 0.69 \mathrm{e}$ & $11.61 \pm 1.36 \mathrm{f}$ \\
8.15 & $28.24 \pm 1.47 \mathrm{~b}$ & $28.57 \pm 1.93 \mathrm{a}$ & $21.14 \pm 1.23 \mathrm{e}$ & $27.12 \pm 1.34 \mathrm{~d}$ & $28.50 \pm 1.92 \mathrm{ab}$ & $21.12 \pm 0.92 \mathrm{e}$ \\
8.29 & $15.65 \pm 0.45 \mathrm{a}$ & $15.09 \pm 0.74 \mathrm{~d}$ & $15.12 \pm 0.45 \mathrm{c}$ & $14.90 \pm 0.29 \mathrm{e}$ & $14.81 \pm 0.71 \mathrm{f}$ & $15.62 \pm 0.85 \mathrm{~b}$ \\
\hline
\end{tabular}

Changes of Titratable Acid Content. The titratable acid content of Z. Jujuba 'Zhanshanmizao' is highest in the young fruit period, and it decreases sharply in the middle and late June, and slightly rises in late July, and then gradually decreases until it is gentle (Table 4). Overall, the titratable acid content of the weak tree was significantly higher than that of the strong tree and the middle tree, and the middle tree was significantly lower than the strong tree. By analysis of variance, Except the strong 
trees on 7.2, the medium tree on 8.15, titratable acid content of the fallen fruit was not significantly different from that of the normal fruit $(p<0.05)$. It can be seen that the fruit drop is not affected by the change of titratable acid content.

Table 4 Titratable acid content in fruit of Z. Jujuba 'Zhanshanmizao'

\begin{tabular}{ccccccc}
\hline \multirow{2}{*}{$\begin{array}{c}\text { Time } \\
\text { (mouth.date) }\end{array}$} & \multicolumn{3}{c}{ Normal fruit $(\%)$} & \multicolumn{3}{c}{ Fallen fruit $(\%)$} \\
\cline { 2 - 7 } & $\begin{array}{c}\text { Strong } \\
\text { tree }\end{array}$ & $\begin{array}{c}\text { Medium } \\
\text { tree }\end{array}$ & $\begin{array}{c}\text { Weak } \\
\text { tree }\end{array}$ & $\begin{array}{c}\text { Strong } \\
\text { tree }\end{array}$ & $\begin{array}{c}\text { Medium } \\
\text { tree }\end{array}$ & $\begin{array}{c}\text { Weak } \\
\text { tree }\end{array}$ \\
\hline 6.18 & $1.01 \pm 0.02 \mathrm{c}$ & $1.03 \pm 0.17 \mathrm{ab}$ & $1.02 \pm 0.09 \mathrm{bc}$ & $1.02 \pm 0.07 \mathrm{bc}$ & $1.04 \pm 0.04 \mathrm{a}$ & $1.03 \pm 0.12 \mathrm{ab}$ \\
7.2 & $0.21 \pm 0.01 \mathrm{~b}$ & $0.20 \pm 0.04 \mathrm{bc}$ & $0.25 \pm 0.06 \mathrm{a}$ & $0.24 \pm 0.01 \mathrm{a}$ & $0.19 \pm 0.02 \mathrm{c}$ & $0.24 \mathrm{a} \pm 0.01$ \\
7.17 & $0.14 \pm 0.02 \mathrm{bc}$ & $0.13 \pm 0.04 \mathrm{c}$ & $0.16 \pm 0.02 \mathrm{a}$ & $0.13 \pm 0.02 \mathrm{c}$ & $0.14 \pm 0.04 \mathrm{bc}$ & $0.16 \pm 0.01 \mathrm{a}$ \\
7.31 & $0.34 \pm 0.10 \mathrm{~b}$ & $0.35 \pm 0.13 \mathrm{~b}$ & $0.37 \pm 0.08 \mathrm{a}$ & $0.35 \pm 0.05 \mathrm{~b}$ & $0.35 \pm 0.06 \mathrm{~b}$ & $0.38 \pm 0.02 \mathrm{a}$ \\
8.15 & $0.25 \pm 0.04 \mathrm{~b}$ & $0.22 \pm 0.05 \mathrm{~d}$ & $0.27 \pm 0.01 \mathrm{a}$ & $0.26 \pm 0.01 \mathrm{ab}$ & $0.24 \pm 0.02 \mathrm{c}$ & $0.28 \pm 0.05 \mathrm{a}$ \\
8.29 & $0.21 \pm 0.01 \mathrm{~b}$ & $0.21 \pm 0.03 \mathrm{~b}$ & $0.25 \pm 0.04 \mathrm{a}$ & $0.22 \pm 0.02 \mathrm{~b}$ & $0.22 \pm 0.07 \mathrm{~b}$ & $0.26 \pm 0.02 \mathrm{a}$ \\
\hline
\end{tabular}

Changes of Vitamin C Content. During fruit development, vitamin C content first rises, peaks in mid-July, then subsequently decreases and then tends to be gentle (Table 5). In the early and middle stages of development, the vitamin $\mathrm{C}$ content of the strong tree was significantly higher than that of the middle and weak tree, but in the middle and late stages, the vitamin $\mathrm{C}$ content of the medium tree was significantly higher than that of the strong tree and weak tree. Except the middle tree on 7.31 and the weak tree on 8.29 , the vitamin $\mathrm{C}$ content in the fallen fruit was significantly lower than the normal fruit, and there was no significant difference between the fallen fruit and the normal fruit in other periods $(p>0.05)$. It is guessed that vitamin $\mathrm{C}$ content is not related to fruit drop during the period of fruit development.

Table 5 Vitamin C content in fruit of Z. Jujuba 'Zhanshanmizao'

\begin{tabular}{ccccccc}
\hline \multirow{2}{*}{$\begin{array}{c}\text { Time } \\
\text { (mouth.date) }\end{array}$} & \multicolumn{3}{c}{ Normal fruit $(\%)$} & \multicolumn{3}{c}{ Fallen fruit $(\%)$} \\
\cline { 2 - 7 } & $\begin{array}{c}\text { Strong } \\
\text { tree }\end{array}$ & $\begin{array}{c}\text { Medium } \\
\text { tree }\end{array}$ & $\begin{array}{c}\text { Weak } \\
\text { tree }\end{array}$ & $\begin{array}{c}\text { Strong } \\
\text { Tree }\end{array}$ & $\begin{array}{c}\text { Medium } \\
\text { tree }\end{array}$ & $\begin{array}{c}\text { Weak } \\
\text { tree }\end{array}$ \\
\hline 6.18 & $52.00 \pm 1.92 \mathrm{a}$ & $47.33 \pm 3.19 \mathrm{~b}$ & $36.67 \pm 2.19 \mathrm{c}$ & $51.67 \pm 4.23 \mathrm{a}$ & $51.67 \pm 3.21 \mathrm{a}$ & $36.43 \pm 2.49 \mathrm{c}$ \\
7.2 & $215.01 \pm 7.28 \mathrm{a}$ & $210.67 \pm 8.52 \mathrm{~b}$ & $197.02 \pm 5.95 \mathrm{c}$ & $213.33 \pm 7.73 \mathrm{a}$ & $213.33 \pm 8.45 \mathrm{a}$ & $195.33 \pm 5.93 \mathrm{c}$ \\
7.17 & $279.52 \pm 3.12 \mathrm{a}$ & $282.76 \pm 5.95 \mathrm{~b}$ & $270.13 \pm 9.24 \mathrm{c}$ & $277.93 \pm 6.72 \mathrm{a}$ & $277.93 \pm 9.35 \mathrm{a}$ & $269.48 \pm 2.76 \mathrm{c}$ \\
7.31 & $217.77 \pm 8.23 \mathrm{c}$ & $224.69 \pm 4.25 \mathrm{a}$ & $203.61 \pm 5.26 \mathrm{~d}$ & $216.13 \pm 6.71 \mathrm{c}$ & $216.13 \pm 9.34 \mathrm{c}$ & $202.33 \pm 3.21 \mathrm{~d}$ \\
8.15 & $230.11 \pm 4.23 \mathrm{~b}$ & $234.68 \pm 8.18 \mathrm{a}$ & $212.42 \pm 6.53 \mathrm{c}$ & $229.73 \pm 9.64 \mathrm{~b}$ & $229.73 \pm 5.99 \mathrm{~b}$ & $211.83 \pm 7.92 \mathrm{c}$ \\
8.29 & $224.73 \pm 5.23 \mathrm{~b}$ & $236.85 \pm 5.27 \mathrm{a}$ & $218.62 \pm 8.48 \mathrm{c}$ & $223.84 \pm 8.21 \mathrm{~b}$ & $223.84 \pm 3.38 \mathrm{~b}$ & $217.35 \pm 8.18 \mathrm{~d}$ \\
\hline
\end{tabular}

\section{Conclusions}

The results of this study indicate that there are two peaks of fruit drop in Z. Jujuba 'Zhanshanmizao', and the first is stronger than the second. The soluble sugar and soluble protein content are closely related to the fruit drop rate, the high content of soluble sugar and soluble protein in jujube fruit can reduce the fruit drop rate and increase the fruit setting rate, however the titratable acid and vitamin $\mathrm{C}$ content had little effect on the fruit drop rate. The tree vigor also has an effect on fruit drop during the fruit development of Z. Jujuba 'Zhanshanmizao', showing the fruit drop rate of weak tree > strong tree $>$ medium tree, the moderate tree vigor of Z. Jujuba 'Zhanshanmizao' can better regulate the balance between vegetative growth and reproductive growth than other two kinds of tree vigores.

\section{Acknowledgements}

This work was financially supported by the Double subject construction plan of Sichuan Agricultural University and Special action plan project of science and technology rich people and strong county of Sichuan Province "Integration and demonstration of key Technologies for industrialized Development of Zizyphus jujuba 'Zhanshangmizao'of Santai County”. 


\section{References}

[1] L. Wang, A.M. Min, Z.G. Qin, Y. Wang and C.G. Li: Journal of West China Forestry Science Vol. 5 (2014), p. 48.

[2] Z.C. Lai and C.X. Ma: Ningxia Journal of Agriculture and Forestry Science and Technology Vol. 4 (2010), p. 94.

[3] J.H. Li and L. Zhou: Shanxi Fruits Vol. 2 (2000), p. 21.

[4] R. Shi: Studies on Jun-jujube fruit drop mechanism and dropping regulation (thesis of master degree, Xinjiang Agricultural University, Urumchi, China 2013).

[5] X.M. Jia, L.Q. Cao and Z.L. W: Northern Horticulture Vol. 1 (2010), p. 11.

[6] Q.H. Li: The Causes of Fruit Dropping of Zizyphus Jujuba cv Lizao and Effect of Girdling on Its Fruit Development and Quality (thesis of master degree, Shandong Agricultural University, Taian, China 2006).

[7] X.F. Xue, A.L. Zhao, H.Y. Ren, C.L. Sui, Y.K. Wang and D.K. Li: Shanxi Fruits Vol. 4 (2014), p. 46.

[8] Z.M. Lu, K. Liu, Z.X. Yan and X.G. Li: Acta Horticulturae Sinica Vol. 37 (2010), p. 2017.

[9] Q.L. Niu, Y.J. Qin, Y. Ding, P.J. Wang and K.J. Yuan: China Fruits Vol. 2 (2017), p. 9.

[10] Q.E. Xiong: Experimental course of Plant Physiology (Sichuan Science and Technology Press, Chengdu, China 2003).

[11] S.Z. Long and Y.Q. He: Journal of Southern Agriculture Vol. 4 (2002), p. 188. 